\title{
Article \\ Hollow CoP/FeP 4 Heterostructural Nanorods Interwoven by CNT as a Highly Efficient Electrocatalyst for Oxygen Evolution Reactions
}

\author{
Yanfang Liu ${ }^{1,2,+}$, Yong $\mathrm{Li}^{1,+}$, Qi Wu ${ }^{1}$, Zhe Su ${ }^{2}$, Bin Wang ${ }^{2, *}$, Yuanfu Chen ${ }^{1,2, *}$ and Shifeng Wang ${ }^{1,3, *}$ \\ 1 College of Science, Institute of Oxygen Supply, Tibet University, Lhasa 850000, China; \\ liuyanfang@utibet.edu.cn (Y.L.); xzuliyong@utibet.edu.cn (Y.L.); wuqi_zangda@163.com (Q.W.) \\ 2 School of Electronic Science and Engineering, and State Key Laboratory of Electronic Thin Films and \\ Integrated Devices, University of Electronic Science and Technology of China, Chengdu 610054, China; \\ su_zhe0412@hotmail.com \\ 3 Key Laboratory of Cosmic Rays, Tibet University, Ministry of Education, Lhasa 850000, China \\ * Correspondence: wangbin403403@126.com (B.W.); yfchen@uestc.edu.cn (Y.C.); wsf@utibet.edu.cn (S.W.) \\ + These authors contribute equally to this work.
}

check for

updates

Citation: Liu, Y.; Li, Y.; Wu, Q.; Su, Z.; Wang, B.; Chen, Y.; Wang, S. Hollow $\mathrm{CoP} / \mathrm{FeP}_{4}$ Heterostructural Nanorods Interwoven by CNT as a Highly Efficient Electrocatalyst for Oxygen Evolution Reactions. Nanomaterials 2021, 11, 1450. https: / / doi.org/10.3390/ nano11061450

Academic Editor: Sónia Carabineiro

Received: 29 April 2021

Accepted: 27 May 2021

Published: 30 May 2021

Publisher's Note: MDPI stays neutral with regard to jurisdictional claims in published maps and institutional affiliations.

Copyright: (C) 2021 by the authors. Licensee MDPI, Basel, Switzerland. This article is an open access article distributed under the terms and conditions of the Creative Commons Attribution (CC BY) license (https:/ / creativecommons.org/licenses/by/ $4.0 /)$.

\begin{abstract}
Electrolysis of water to produce hydrogen is crucial for developing sustainable clean energy and protecting the environment. However, because of the multi-electron transfer in the oxygen evolution reaction (OER) process, the kinetics of the reaction is seriously hindered. To address this issue, we designed and synthesized hollow $\mathrm{CoP} / \mathrm{FeP}_{4}$ heterostructural nanorods interwoven by carbon nanotubes $\left(\mathrm{CoP} / \mathrm{FeP}_{4} @ \mathrm{CNT}\right)$ via a hydrothermal reaction and a phosphorization process. The CoP/FeP 4 @CNT hybrid catalyst delivers prominent OER electrochemical performances: it displays a substantially smaller Tafel slope of $48.0 \mathrm{mV} \mathrm{dec}^{-1}$ and a lower overpotential of $301 \mathrm{mV}$ at $10 \mathrm{~mA} \mathrm{~cm}{ }^{-2}$, compared with an $\mathrm{RuO}_{2}$ commercial catalyst; it also shows good stability over $20 \mathrm{~h}$. The outstanding OER property is mainly attributed to the synergistic coupling between its unique CNT-interwoven hollow nanorod structure and the $\mathrm{CoP} / \mathrm{FeP}_{4}$ heterojunction, which can not only guarantee high conductivity and rich active sites, but also greatly facilitate the electron transfer, ion diffusion, and $\mathrm{O}_{2}$ gas release and significantly enhance its electrocatalytic activity. This work offers a facile method to develop transition metal-based phosphide heterostructure electrocatalysts with a unique hierarchical nanostructure for high performance water oxidation.
\end{abstract}

Keywords: $\mathrm{CoP}-\mathrm{FeP}_{4}$ heterojunction; hollow nanorods; oxygen evolution reaction

\section{Introduction}

As a kind of sustainable and clean energy, hydrogen has great application prospects for promoting the commercialization of fuel cells. At present, splitting water is a promising hydrogen generation technology that can not only alleviate the consumption of many fossil fuels, but also protect the environment [1,2]. In the process of water electrolysis, the oxygen evolution reaction (OER) at the anode determines the work efficiency of the whole process. Nevertheless, the process of OER involves multiple electron transfer steps so that it has sluggish reaction dynamics [3-6]. Although $\mathrm{RuO}_{2}$ and $\mathrm{IrO}_{2}$ have been considered as good commercial catalysts for OER, the large-scale application of $\mathrm{RuO}_{2}$ and $\mathrm{IrO}_{2}$ for OER is limited by the resource scarcity and high cost [7-9]. Consequently, it is becoming hugely important to develop OER catalysts with low cost, high efficiency and excellent long-term stability [10].

Many researchers have made great efforts to explore the non-noble metal catalysts, such as transition metal hydroxides (e.g., $\left.\mathrm{CoFe}(\mathrm{OH})_{x}[11]\right)$, oxides (e.g., $\left.\mathrm{CoO}_{\mathrm{x}}[12]\right)$, phosphides (e.g., NiFeP [13]), selenides (e.g., WSe 2 [14]), sulfides (e.g., $\mathrm{Co}_{8} \mathrm{FeS}_{8}$ [15]), nitrides (e.g., CoFe-N [16]) and carbides (e.g., $\mathrm{Mo}_{2} \mathrm{C}$ [17]) [18-20]. Among all the catalyst types, transition metal phosphides (TMPs) have become the research focus due to their high 
activity and low cost. However, the electrochemical properties of pure transition metal phosphides are far from as expected. As a result, many researchers have begun to improve the performance of OER in various aspects, such as manipulating the morphology of materials, creating defects, forming heterojunctions and doping extrinsic atoms. At the same time, some bimetallic layered hydroxides also exhibit good stability and expose a large number of active sites due to their unique layered structure. However, the strategies mentioned above are not efficient to improve the electrical conductivity and enlarge the electrochemically active areas. In order to address such issues, introducing highly conductive carbon nanotubes (CNTs) or graphene into the catalyst during the synthesis process have been widely considered [21,22].

Great progress on improving the catalytic activity has been made. For example, Yue et al. [11] first synthesized $\mathrm{Cu}_{2} \mathrm{O}$ micropolyhedra as the sacrificial template using a coprecipitation method, and then synthesized $\mathrm{CoFe}(\mathrm{OH})_{x}$ hollow microspheres at room temperature, showing strong stability and excellent electrochemical activity for OER with an overpotential of $293 \mathrm{mV}$ at $10 \mathrm{~mA} \mathrm{~cm}^{-2}$ and a Tafel slope of $67.4 \mathrm{mV} \mathrm{dec}^{-1}$, respectively. Zhou et al. [23] synthesized two-dimensional bimetalline CoFe selenide using a simple metal ion self-assembly method under hydrothermal conditions, with an overpotential of $257 \mathrm{mV}$ and a low Tafel slope of $45.6 \mathrm{mV} \mathrm{dec}^{-1}$ at $10 \mathrm{~mA} \mathrm{~cm}^{-2}$. The outstanding electrochemical activity of OER is attributed to the unique two-dimensional layered structure of the catalysts, which are conducive to charge transfer and ion diffusion. Liu et al. [24] synthesized CoFe bimetallic layered hydroxide composite with $\mathrm{N}$-doped carbon nanotubes, which showed durable stability. The introduction of CNT increased the specific surface area of electrochemical activity and conductivity as well. The preparation process was carried out by a simple one-pot method at room temperature, generating an overpotential of $270 \mathrm{mV}$ at $10 \mathrm{~mA} \mathrm{~cm}^{-2}$, and a Tafel slope of $56.88 \mathrm{mV} \mathrm{dec}^{-1}$. However, it is still difficult to develop a highly efficient and stable CNT-composited bimetallic compound OER catalyst with unique nanoarchitecture and abundant catalytic sites.

To address these issues, we designed and synthesized hollow $\mathrm{CoP} / \mathrm{FeP}_{4}$ heterostructural nanorods interwoven by carbon nanotubes $\left(\mathrm{CoP} / \mathrm{FeP}_{4} @ \mathrm{CNT}\right)$ via a hydrothermal reaction and subsequent phosphorization. This hollow heterostructure hybrid catalyst delivers prominent OER electrochemical performances: it displays an extremely smaller Tafel slope of $48.0 \mathrm{mV} \mathrm{dec}^{-1}$ and a lower overpotential of $301 \mathrm{mV}$ at $10 \mathrm{~mA} \mathrm{~cm}^{-2}$, compared with a $\mathrm{RuO}_{2}$ commercial catalyst; it also shows good stability over $20 \mathrm{~h}$. The excellent OER performance is mainly due to its unique hollow nanorod structure interwoven with conductive CNT, which guarantees high conductivity and enriches active sites. These merits greatly facilitate the electron transfer, ion diffusion, and $\mathrm{O}_{2}$ gas release, which significantly enhance its electrocatalytic activity. This work provides a promising strategy for the synthesis of a hollow transition-metal phosphide heterostructure with an efficient OER performance.

\section{Materials and Methods}

\subsection{Materials}

Cobalt nitrate hexahydrate $\left(\mathrm{Co}\left(\mathrm{NO}_{3}\right)_{2} \cdot 6 \mathrm{H}_{2} \mathrm{O}\right)$, iron(III) nitrate nonahydrate $\left(\mathrm{Fe}\left(\mathrm{NO}_{3}\right)_{3}\right.$ $9 \mathrm{H}_{2} \mathrm{O}$ ), carbon nanotube paste (5\% CNT in NMP), and ethanol were purchased from Aladdin, Co. Ltd. (Seoul, Korea). Ruthenium oxide ( $\mathrm{RuO}_{2}$ electrocatalyst), and Nafion solution were received from shanghai Macklin Ltd. All chemical reagents were analytical grade and used without further purification; double distilled water/ethanol mixtures were used as washing solvents throughout the investigations.

\subsection{Synthesis of CoFe-LDH@CNT}

CoFe-LDH@CNT was synthesized according to the method of the previous report with a slight change [1]. Firstly, $1.2 \mathrm{~g}$ of CNT slurry was taken and dispersed into $60 \mathrm{~mL}$ of deionized water for an ultrasound for $30 \mathrm{~min}$ until the uniform black suspension was formed. Secondly, $404 \mathrm{mg}$ of $\mathrm{Fe}\left(\mathrm{NO}_{3}\right)_{3} \cdot 9 \mathrm{H}_{2} \mathrm{O}, 292 \mathrm{mg}$ of $\mathrm{Co}\left(\mathrm{NO}_{3}\right)_{2} \cdot 6 \mathrm{H}_{2} \mathrm{O}, 1.21 \mathrm{~g}$ of 
$\mathrm{CO}\left(\mathrm{NH}_{2}\right)_{2}$ and $297 \mathrm{mg}$ of $\mathrm{NH}_{4} \mathrm{~F}$ were poured into the above suspension and magnetically stirred for an additional $30 \mathrm{~min}$. Finally, the solution was transferred into a stainless steel autoclave, heated to $120^{\circ} \mathrm{C}$ for $12 \mathrm{~h}$. After cooling down naturally, the sample was collected using suction filtration, washed with deionized water and ethanol several times, and then placed in a freeze-dryer to dry overnight. The dried product is lump-like and needs to be ground into powder with a mortar for subsequent testing and characterizations. For comparison, the preparation process for CoFe-LDH and CoFe-LDH@CNT was similar apart from the addition of CNT slurry.

\subsection{Synthesis of $\mathrm{CoP} / \mathrm{FeP} \mathrm{P}_{4} @ \mathrm{CNT}$ nanorods}

CoFe-LDH@CNT and $\mathrm{NaH}_{2} \mathrm{PO}_{2}$ with a weight ratio of 1:10 were put on two separate quartz boats with $\mathrm{NaH}_{2} \mathrm{PO}_{2}$ powder at the upstream side of the tube furnace. The phosphorization process was carried out in argon, and the temperature was raised to $400{ }^{\circ} \mathrm{C}$ for $2 \mathrm{~h}$ at a heating rate of $3^{\circ} \mathrm{C} \mathrm{min}^{-1}$. When the temperature in the furnace was cooled to room temperature, the resulting sample was recorded as $\mathrm{CoP} / \mathrm{FeP}_{4} @ \mathrm{CNT}$. Using CoFe-LDH as the precursor, we synthesized the CoFeP sample.

\subsection{Characterizations}

The crystal structure of the as-obtained CoP/FeP $@$ @CNT was analyzed through Xray diffraction (Palmer naco X'Pert PRO). The Raman spectrum of $\mathrm{CoP} / \mathrm{FeP}_{4} @ \mathrm{CNT}$ was conducted with a $532 \mathrm{~nm}$ excitation laser (Renishaw). The surface chemical composition and electronic structure of $\mathrm{CoP} / \mathrm{FeP}_{4} @ \mathrm{CNT}$ were examined by an X-ray photoelectron spectroscope on a Thermo Scientific K-Alpha. The morphology of the sample was observed using a United States FEI Inspect F50 Scanning eletronmicroscope (SEM) and an FEI Talos F200x (TEM) equipped with an energy dispersive X-ray detector (EDX, Brooke quantax).

\subsection{Electrocatalytic Measurements}

All electrochemical performance tests in the OER process were performed on an electrochemical workstation (CHI660D) with a three-electrode system, and $1 \mathrm{M} \mathrm{KOH}$ solution was used as the electrolyte. Generally, the graphite rod was used as the counter electrode, $\mathrm{Hg} / \mathrm{HgO}$ electrode as the reference electrode, and the glassy carbon electrode as the working electrode. In all measurements, potential values were changed to a reversible hydrogen electrode (RHE): $\mathrm{E}_{\mathrm{RHE}}=\mathrm{E}_{\mathrm{Hg} / \mathrm{HgO}}+0.923 \mathrm{~V}$. Before the electrocatalytic test, the scan of at least 20 cycles of cyclic voltammetry (CV) was performed at $100 \mathrm{mV} \mathrm{s}^{-1}$ to ensure to obtain stable curves. Line scan voltammogram (LSV) curves have a potential range of 0 to $0.8 \mathrm{~V}$ at a scanning rate of $5 \mathrm{mv} \mathrm{s}^{-1}$. The double-layer capacitance (Cdl) was also calculated from cyclic voltammogram $(\mathrm{CV})$ data in $1 \mathrm{M} \mathrm{KOH}$ solution, which require sweeping rates from $20 \mathrm{mV} \mathrm{s}^{-1}$ to $200 \mathrm{mV} \mathrm{s}^{-1}$ over a range of potential tests, with a step of $20 \mathrm{mV} \mathrm{s}^{-1}$ for each curve. The electrochemical impedance spectroscopy (EIS) tests were performed from $100 \mathrm{kHz}$ to $0.1 \mathrm{~Hz}$. The stability of $\mathrm{CoP} / \mathrm{FeP}_{4} @ \mathrm{CNT}$ was evaluated by continuous chronoamperometry using nickel foam $(1 \times 1 \mathrm{~cm})$, and the holding potential for the chronoamperometry test was $1.533 \mathrm{~V}$.

\section{Results}

The schematic diagram of $\mathrm{CoP} / \mathrm{FeP}_{4} @ \mathrm{CNT}$ preparation is clearly presented in Figure 1. Firstly, the CoFe-LDH@CNT nanorod precursor was synthesized by the hydrothermal method, and then the material was further modified by phosphorization. Importantly, the subsequent experimental data showed that the catalytic performance of the catalyst was significantly improved after phosphorization, which was ascribed to the synergistic effects of different phases. 


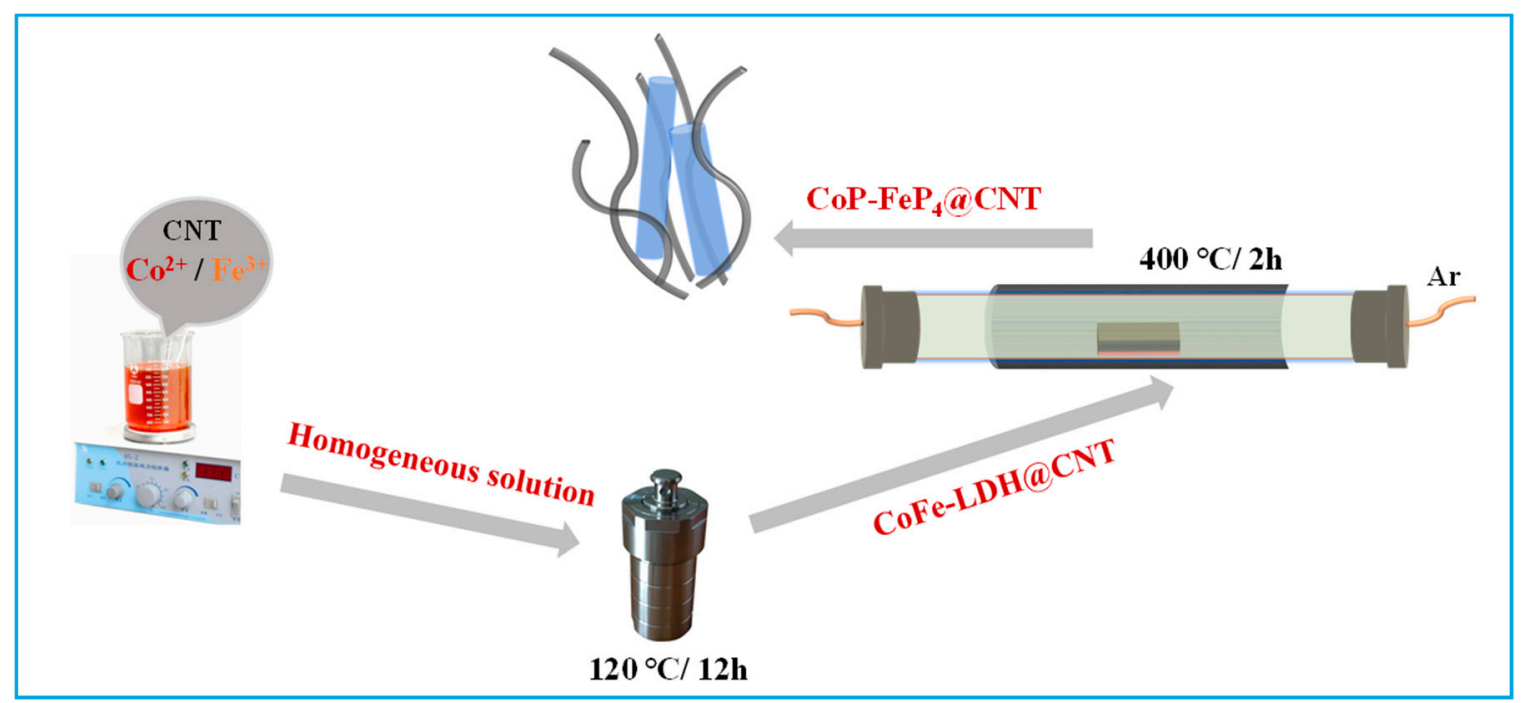

Figure 1. A two-step fabrication process of $\mathrm{CoP} / \mathrm{FeP}_{4} @ \mathrm{CNT}$ nanorods.

The X-ray diffraction (XRD) pattern (Figure 2a) demonstrates that the characteristic peaks of $\mathrm{CoP} / \mathrm{FeP}_{4} @ \mathrm{CNT}$ match well with the standard patterns of CoP (PDF no. 29-0497) and $\mathrm{FeP}_{4}$ (PDF no. 71-0473). Moreover, the peaks at $26.6^{\circ}$ and $43.4^{\circ}$ correspond to (111) and (010) of CNT (PDF No. 75-0473). The peaks at $32.6^{\circ}, 36.7^{\circ}$ and $52.2^{\circ}$ are (131), (112), and (133) planes of $\mathrm{FeP}_{4}$; the peaks at $31.9^{\circ}, 36.7^{\circ}, 46.5^{\circ}, 48.4^{\circ}, 52.2^{\circ}$ and $56.7^{\circ}$ correspond to (011), (102), (112), (202), (103), and (301) planes of CoP. In addition, as shown in Figure S1, the prominent peaks of the CoFe-LDH@CNT precursor correspond perfectly to $\mathrm{FeO}(\mathrm{OH})$ (PDF No. 34-1266) and CoOOH (PDF No. 26-0480). The Raman spectrum shows two obvious peaks at $1347 \mathrm{~cm}^{-1}$ and $1582 \mathrm{~cm}^{-1}$, respectively, corresponding to the D peak and $\mathrm{G}$ peak of CNT, as displayed in Figure 2b. The D peak associates with the defect of the carbon crystal, and the $G$ peak demonstrates the in-plane stretching vibration of the $\mathrm{sp}^{2}$ hybridization of carbon. The band intensity ratio $\left(\mathrm{I}_{\mathrm{D}} / \mathrm{I}_{\mathrm{G}}\right)$ of the CoP/FeP $@ \mathrm{CNT}$ nanorods was 1.11, suggesting the formation of lattice defects during the phosphidation process. Furthermore, the Raman spectrum was deconvoluted into four peaks, according to previous research [25]. The peaks at $1325 \mathrm{~cm}^{-1}$ (1) and $1485 \mathrm{~cm}^{-1}$ (3) are related to $\mathrm{sp}^{3}$-type carbon, and the other two spectra at around $1357.3 \mathrm{~cm}^{-1}$ (2) and $1590.3 \mathrm{~cm}^{-1}$ (4) are associated with $\mathrm{sp}^{2}$-type carbon. The integrated area ratio of $\mathrm{sp}^{3}$ to $\mathrm{sp}^{2}\left(\mathrm{~A}_{\mathrm{sp} 3} / \mathrm{A}_{\mathrm{sp} 2}\right)$ is 0.98 , inferring that the amount of $\mathrm{sp}^{3}$-type carbon is nearly the same as the $\mathrm{sp}^{2}$-type carbon. Importantly, the catalytic activity of the metal phosphides is related to the surface properties of the material on the one hand and the internal structure on the other hand. Therefore, the electrochemical performance can be improved by increasing the number of exposed active sites, as well as adjusting the morphology, defects and active surface area of the material.

X-ray photoelectron spectroscopy (XPS) was used to analyze the type of elements contained in $\mathrm{CoP} / \mathrm{FeP}_{4} @ \mathrm{CNT}$ and the chemical valence states presented in various elements. As shown in Figure S2, the XPS survey spectrum proves the existence of $\mathrm{C}, \mathrm{O}, \mathrm{Co}$, $\mathrm{Fe}, \mathrm{P}$. Meanwhile, Figure 3 also shows the high-resolution XPS patterns of $\mathrm{C}, \mathrm{Co}, \mathrm{Fe}$ and $\mathrm{P}$, respectively. There are three distinct characteristic peaks in the XPS of $\mathrm{C} 1 \mathrm{~s}$, which are located at 283.7, 284.5 and $289.3 \mathrm{eV}$ corresponding to $\mathrm{C}-\mathrm{C}, \mathrm{C}-\mathrm{O}$ and $\mathrm{O}-\mathrm{C}=\mathrm{O}$, respectively (Figure 3a). The Co 2p XPS spectrum shows two peaks at $778.2 \mathrm{eV}$ (Co 2p3/2) and $793.2 \mathrm{eV}$ (Co 2p1/2) which are assigned to the Co-P bond, and there are another two satellites (Sat.) at 783.3 and $802.2 \mathrm{eV}$. The other peaks at 780.7 and $797.1 \mathrm{eV}$ correspond to the $\mathrm{Co}-\mathrm{O}$ band, which might be due to the sample being oxidized in air (Figure 3b). As shown in Figure $3 c$, there are two peaks at $706.5 \mathrm{eV}(\mathrm{Fe} 2 \mathrm{p} 3 / 2)$ and $719.5 \mathrm{eV}(\mathrm{Fe} 2 \mathrm{p} 1 / 2)$ in the XPS spectrum of Fe $2 \mathrm{p}$, indicating the presence of a Fe-P bond. The obvious peaks at 710.6 and $723.2 \mathrm{eV}$, which can be considered as the oxidation state of Fe, and the satellite peaks at 
714.1 and $725.6 \mathrm{eV}$ are generated by the oscillation of excited electrons. In Figure $3 \mathrm{~d}$, the XPS spectrum of $\mathrm{P} 2 \mathrm{p}$ can be deconvoluted into four distinct peaks at 128.8, 129.7, 132.3 and $133.3 \mathrm{eV}$ corresponding to $\mathrm{P} 2 \mathrm{p}_{3 / 2}, \mathrm{P} 2 \mathrm{p}_{1 / 2}, \mathrm{P}-\mathrm{C}$, and $\mathrm{P}-\mathrm{O}$, respectively, which represent different chemical states of element $\mathrm{P}$ [26-30].
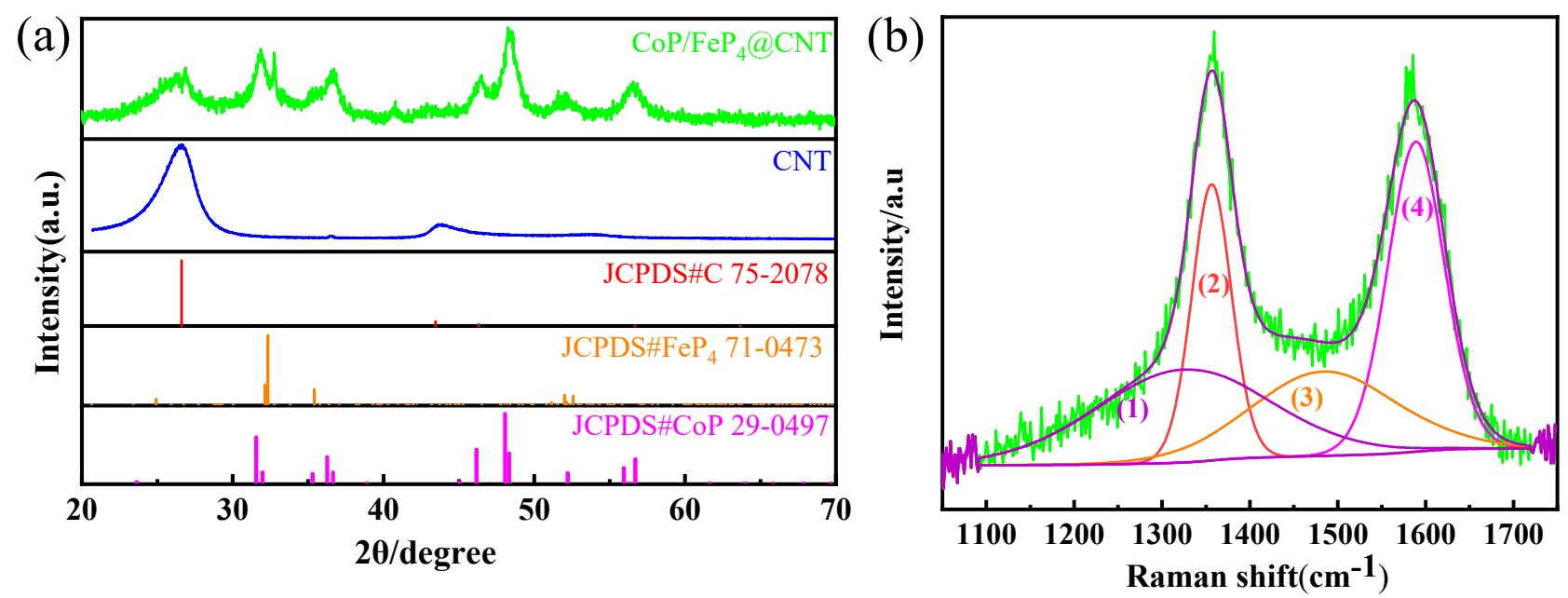

Figure 2. (a) The XRD pattern of the $\mathrm{CoP} / \mathrm{FeP}_{4} @ \mathrm{CNT}$ and CNT, (b) Raman spectrum of the CoP/FeP $@$ @CNT.

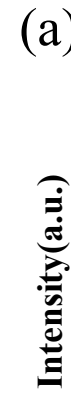

(a)
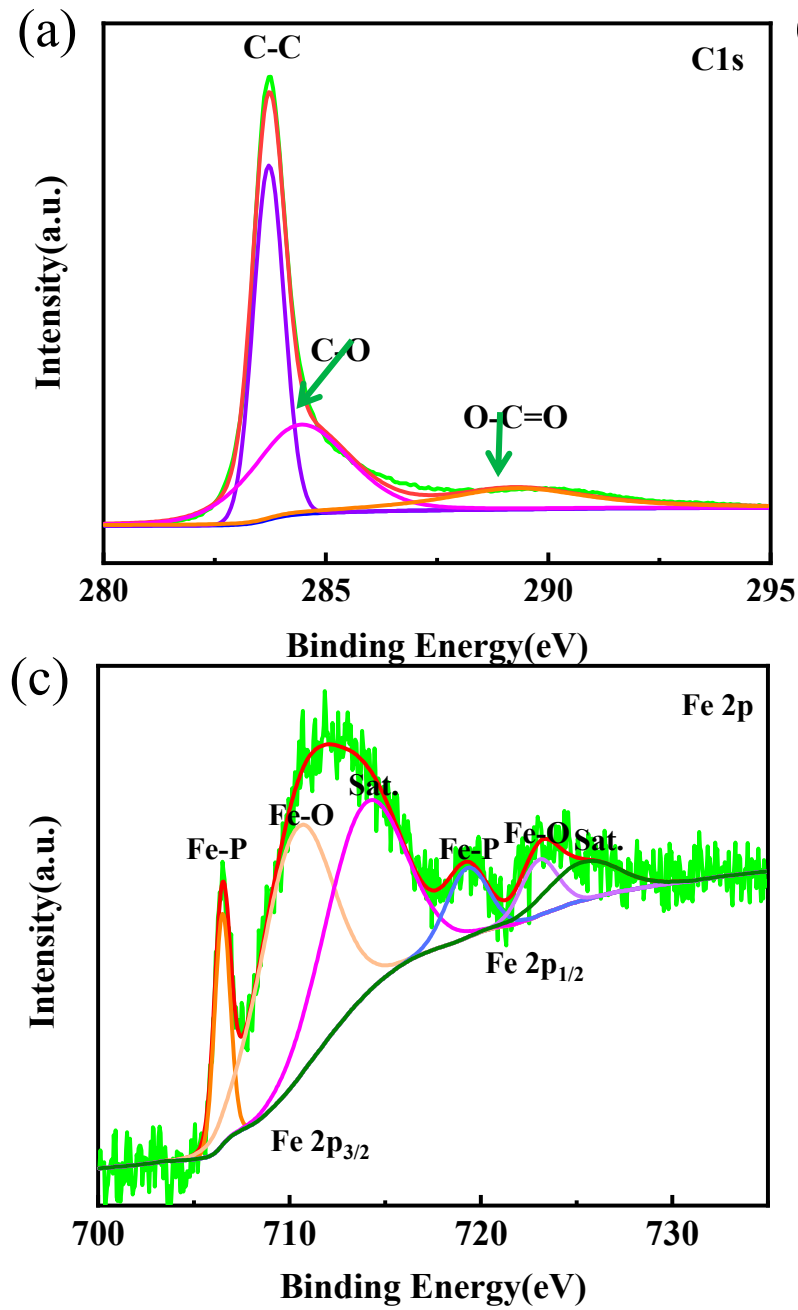

(b)

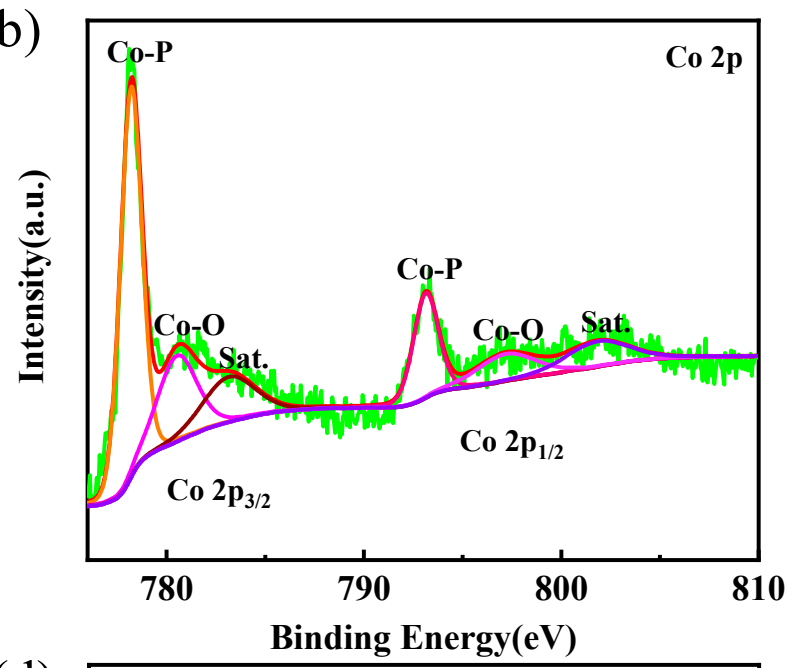

(d)

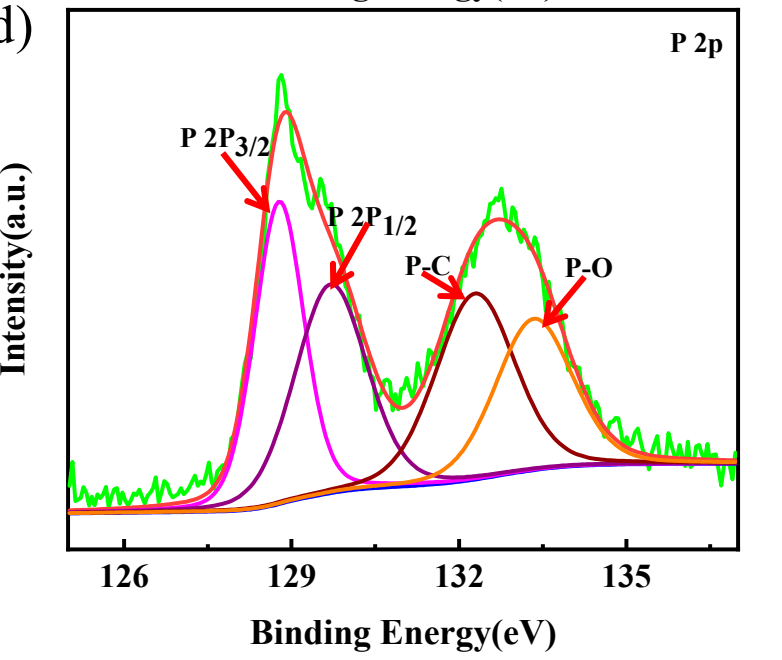

Figure 3. (a-d) The XPS spectra of (a) C 1s, (b) Co 2p, (c) Fe 2p and (d) P 2p of CoP/FeP $@$ @CNT nanorods. 
The scanning electron microscopy (SEM) images show that both morphologies of CoFe-LDH and CoFe-LDH@CNT precursors are nanorods (Figures S3 and S4). At the same time, it can be observed that $\mathrm{CoFe}-\mathrm{LDH}$ nanorods are mostly slender, while CoFeLDH@CNT nanorods are short and thick. Strangely, almost all the nanorods showed a hollow structure after CoFe-LDH phosphorization, and only a small amount of nanorods contained nanoparticles, indicating that the phosphorization process can play a certain etching role. As shown in Figure $4 \mathrm{a}$, the $\mathrm{CoP} / \mathrm{FeP}_{4} @ \mathrm{CNT}$ nanorods are clearly obtained after phosphorization for CoFe-LDH@CNT, and it is also found that the original morphology does not change after phosphorization. The unique difference is the formation of hollow nanorods after phosphorization, which could well explain the significant enhancement in the electrochemical performance after phosphorization. The hollow nanorods provide a channel for electron transfer, which is beneficial to speed up the reaction.
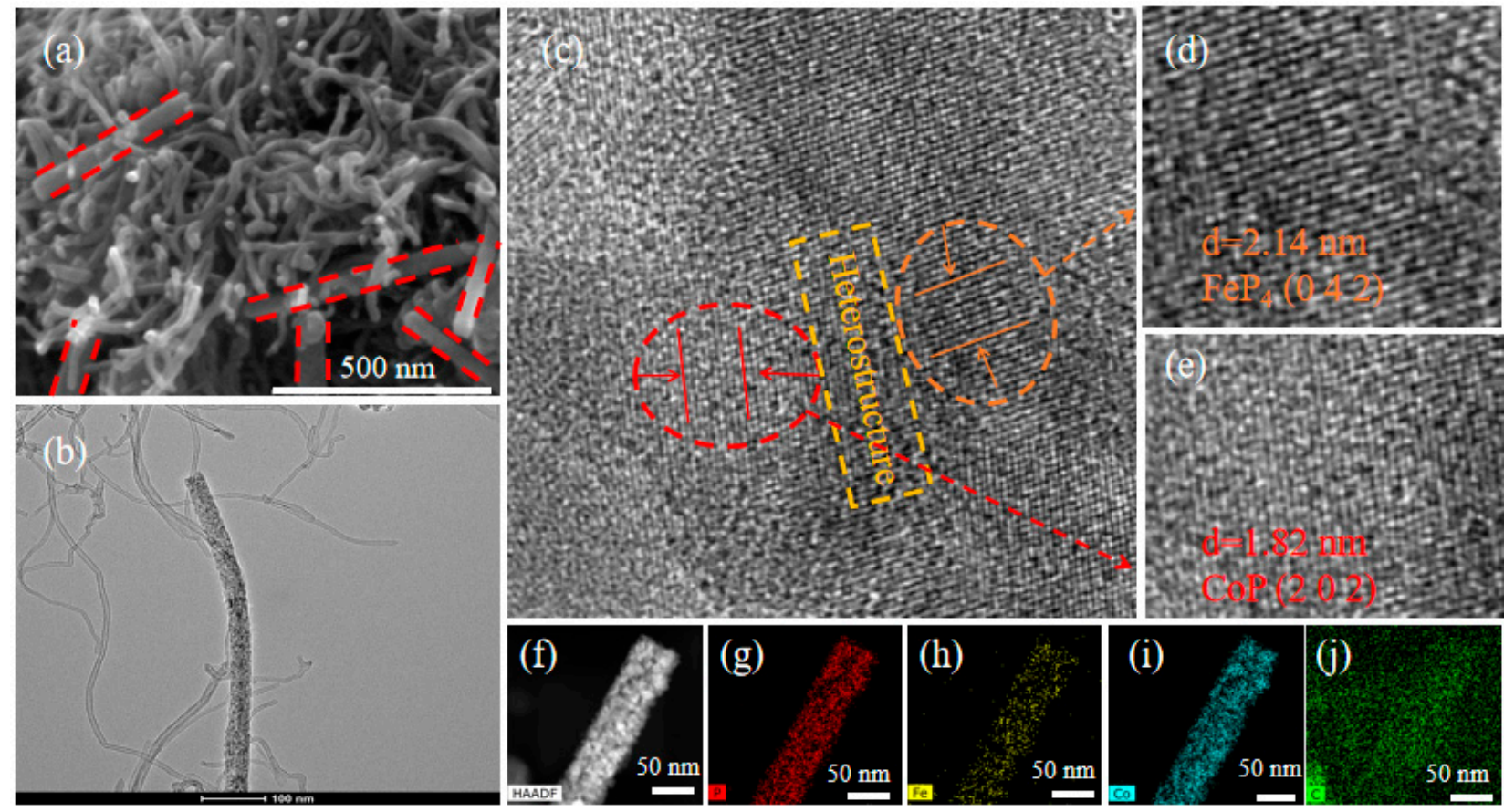

Figure 4. (a,b) SEM and TEM, (c) HRTEM, (d,e) are magnifications of the orange and red areas in (c), respectively, and the value of $d$ in the diagram $(\mathbf{d}, \mathbf{e})$ represents the width of the 10 lattice stripes. (f) HAADF-STEM and (g-j) elemental mapping of $\mathrm{CoP} / \mathrm{FeP}_{4} @ \mathrm{CNT}$.

In Figure $4 \mathrm{~b}$, the transmission electron microscopy (TEM) image clearly presents that the diameter of $\mathrm{CoP} / \mathrm{FeP}_{4} @ \mathrm{CNT}$ hollow nanorods is about $40 \mathrm{~nm}$. The crystal lattice fringes in the orange circle region in Figure 4c corresponds to the (0 4 2) crystal plane of $\mathrm{FeP}_{4}$ (Figure 4d), and lattice fringes in the red circle region in Figure 4e corresponds to the (2 0 2) crystal plane of CoP; these results are consistent with XRD data (Figure 2a) [31,32]. It is worth noting that the middle yellow rectangular area depicts the formation of heterojunctions during phosphorization. Therefore, another reason for the excellent catalytic properties after phosphorization can be put down to the enhancement effect between the phases of the two metal phosphides. In addition, the high-angle annular dark-field scanning TEM (HAADF-STEM) image (Figure 4f) and the element mapping images (Figure $4 \mathrm{~g}-\mathrm{j}$ ) show that the $\mathrm{C}, \mathrm{Co}, \mathrm{Fe}$ and $\mathrm{P}$ are uniformly distributed in the material. Meanwhile, this information can also be further verified by the EDX data (Figure S5).

The electrochemical tests of all samples were conducted in a $1 \mathrm{M} \mathrm{KOH}$ solution with a glassy carbon electrode as the working electrode. In Figure 5a, the CoFe-LDH precursor without CNT showed the worst catalytic activity, with an overpotential of $485 \mathrm{mV}$ (at $\left.10 \mathrm{~mA} \mathrm{~cm}^{-2}\right)$ and an extremely high Tafel slope $\left(114 \mathrm{mV} \mathrm{dec}^{-1}\right)$. In contrast, the precursor 
CoFe-LDH@CNT exhibits excellent catalytic activity with an overpotential of $355 \mathrm{mV}$ and a relatively low Tafel slope of only $49 \mathrm{mV} \mathrm{dec}^{-1}$. Therefore, the better catalytic activity of the CoFe-LDH@CNT is ascribed to the high conductivity and a large electrochemical activity specific surface area provided by the CNT networks. Next, the differences between the electrochemical properties of the precursor (CoFe-LDH and CoFe-LDH@CNT) and the phosphide (CoFeP and $\mathrm{CoP} / \mathrm{FeP}_{4} @ \mathrm{CNT}$ ) were compared. Similarly, the compounds with CNT performed better than those without CNT. Another important finding was that both the required overpotential and the Tafel slope of the phosphide at $10 \mathrm{~mA} \mathrm{~cm}{ }^{-2}$ performed better than those of the precursors. Therefore, it is safe to conclude that the catalytic activity of the material can be enhanced through the phosphorization process.

(a)

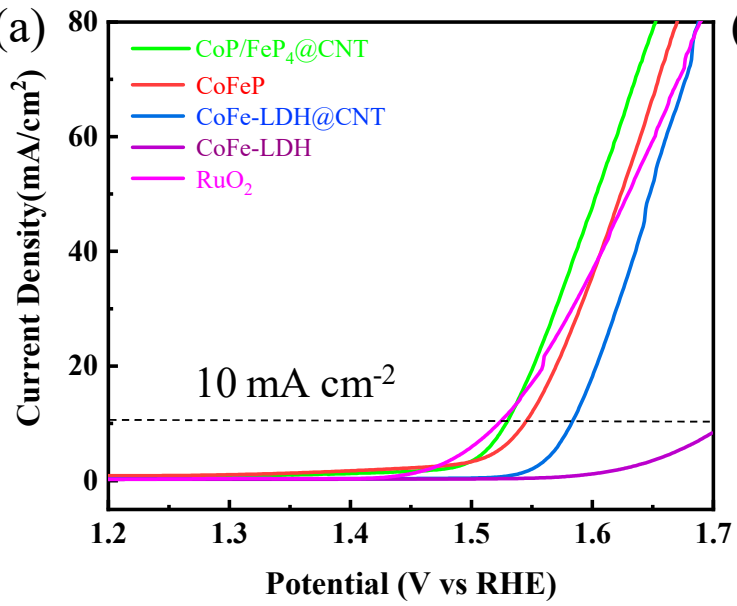

(c)

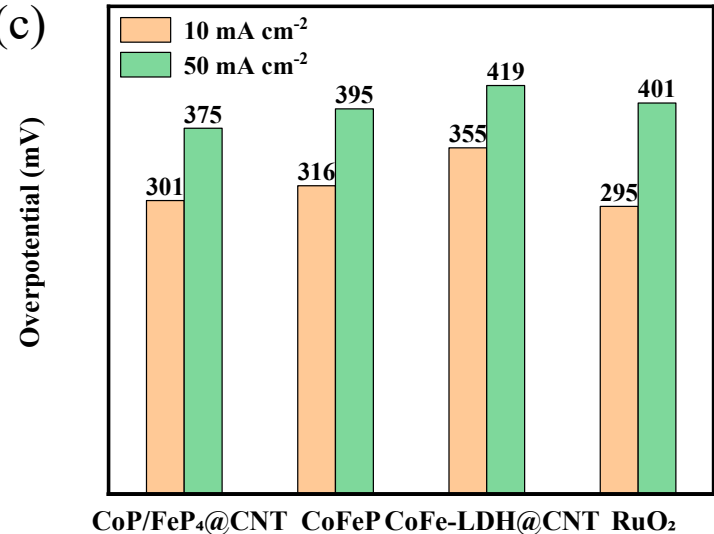

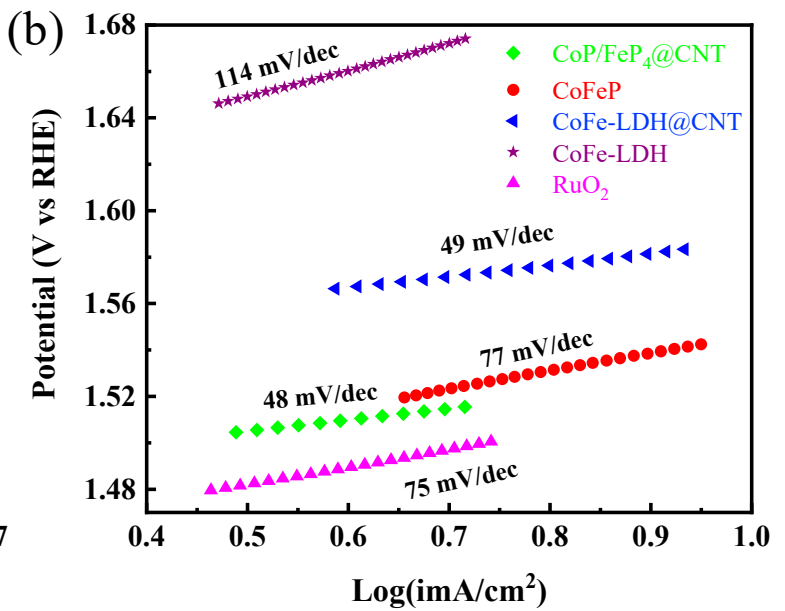

(d)

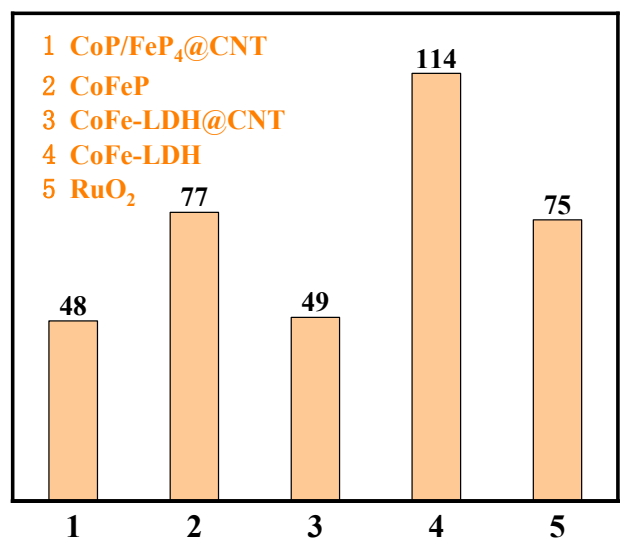

Figure 5. (a) LSV curves in $1 \mathrm{M} \mathrm{KOH}$ solution, (b) Tafel plots, (c) the potential of $10 \mathrm{~mA} \mathrm{~cm}{ }^{-2}$ and $50 \mathrm{~mA} \mathrm{~cm}^{-2}$, (d) the bar graph of the Tafel plots.

In Figure 5c, CoP/FeP 9 @ NT displays a lower overpotential of $301 \mathrm{mV}$ compared with other samples at the current density of $10 \mathrm{~mA} \mathrm{~cm}^{-2}$. Meanwhile, CoP/FeP $@ \mathrm{CNT}$ exhibits the optimal Tafel slope $\left(48 \mathrm{mV} \mathrm{dec}^{-1}\right)$ among all the samples. Although the as-prepared $\mathrm{CoP} / \mathrm{FeP}_{4} @ \mathrm{CNT}$ demonstrates a lager overpotential than that of the commercial $\mathrm{RuO}_{2}$ at $10 \mathrm{~mA} \mathrm{~cm}^{-2}$, it surpasses $\mathrm{RuO}_{2}$ when the current density increases. For example, at the current density of $50 \mathrm{~mA} \mathrm{~cm}{ }^{-2}$, the potential of $\mathrm{CoP} / \mathrm{FeP}_{4} @ \mathrm{CNT}$ is only $375 \mathrm{mV}$, while that of $\mathrm{RuO}_{2}$ is $401 \mathrm{mV}$ and $\mathrm{CoP} / \mathrm{FeP}_{4} @ \mathrm{CNT}$ behaves best at a high current density, as shown in Figure 5c. By comparing the Tafel slopes of all the tested samples, the $\mathrm{CoP} / \mathrm{FeP}_{4} @ \mathrm{CNT}$ is the minimum, which is anastomotic with the results of the LSV. Therefore, an important conclusion can be drawn that $\mathrm{CoP} / \mathrm{FeP}_{4} @ \mathrm{CNT}$ possesses a better dynamic performance for the OER.

In order to fully understand the origin of the outstanding electrochemical performance of $\mathrm{CoP} / \mathrm{FeP}_{4} @ \mathrm{CNT}$, the electrochemical double-layer capacitances $\left(\mathrm{C}_{\mathrm{dl}}\right)$ were examined by operating cyclic voltammograms $(\mathrm{CVs})$ in a current range, which can directly estimate 
the electrochemical active surface area (ECSA). Specifically, CVs with different scan rates (20-200 $\mathrm{mV} \mathrm{s}^{-1}$ ) are demonstrated in a potential range between 1.203 and $1.303 \mathrm{~V}$ (vs. RHE). As shown in Figure 6a, the $\mathrm{C}_{\mathrm{dl}}$ of $\mathrm{CoP} / \mathrm{FeP}_{4} @ \mathrm{CNT}\left(29.75 \mathrm{mF} \mathrm{cm}^{-2}\right)$ is higher than that of $\mathrm{CoFeP}\left(16.58 \mathrm{mF} \mathrm{cm}^{-2}\right)$, CoFe-LDH@CNT $\left(5.83 \mathrm{mF} \mathrm{cm}^{-2}\right)$ and CoFe-LDH $\left(0.37 \mathrm{mF} \mathrm{cm}^{-2}\right)$. The large $\mathrm{C}_{\mathrm{dl}}$ of $\mathrm{CoP} / \mathrm{FeP}_{4} @ \mathrm{CNT}$ indicates a substantially large active surface area, which is beneficial for charge transfer and ion diffusion. In Figure S6, the CVs of all samples were shown at the different scan rates. In addition, $\mathrm{CoP} / \mathrm{FeP}_{4} @ \mathrm{CNT}$ displays the smallest semicircle diameter in electrochemical impedance spectroscopy (EIS) in Figure 6b, which indicated that $\mathrm{CoP} / \mathrm{FeP}_{4} @ \mathrm{CNT}$ possesses the minimum electrochemical impedance and the fastest charge transfer rate [33]. In order to get the aperture information for the $\mathrm{CoP} / \mathrm{FeP}_{4} @ \mathrm{CNT}$, the $\mathrm{BET}$ test was acquired through $\mathrm{N}_{2}$ adsorption-desorption-isotherm in Figure 6c. The CoP/FeP $@$ @CNT shows a BET surface area of $71.057 \mathrm{~m}^{2} \mathrm{~g}^{-1}$, which is ten times that of $\mathrm{CoFeP}\left(7.690 \mathrm{~m}^{2} \mathrm{~g}^{-1}\right)$ [34-36]. Additionally, the distribution of pore size obtained from the Barrett-Joyner-Halenda (BJH) method is presented in Figure $6 \mathrm{~d}$. The $\mathrm{CoP} / \mathrm{FeP}_{4} @ \mathrm{CNT}$ shows that the pore size has a great probability at the range of $2-5 \mathrm{~nm}$ and $20-40 \mathrm{~nm}$, confirming the existence of micropores and mesopores. However, $\mathrm{CoFeP}$ mainly exists in the form of micropores, which can perfectly explain why $\mathrm{CoP} / \mathrm{FeP}_{4} @ \mathrm{CNT}$ has more of an outstanding performance than $\mathrm{CoFeP}$ : the large pores make it easier for electrons to pass through and speed up the reaction.
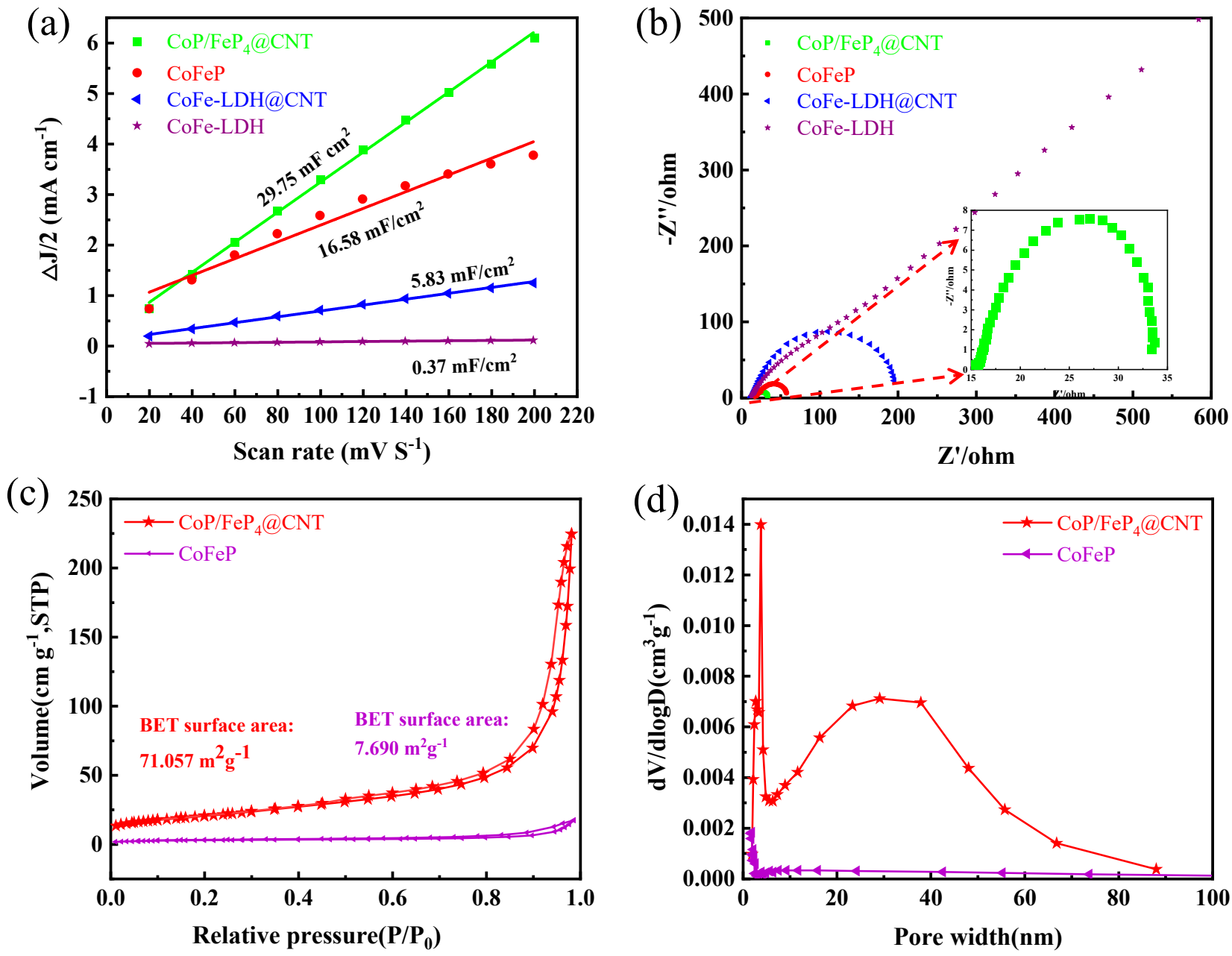

Figure 6. (a) Estimated $\mathrm{C}_{\mathrm{dl}}$ values and relative electrochemically active surface areas, and (b) Nyquist plots of $\mathrm{CoP} / \mathrm{FeP}_{4} @ \mathrm{CNT}, \mathrm{CoFeP}, \mathrm{CoFe}-\mathrm{LDH} @ \mathrm{CNT}$ and CoFe-LDH. The inset of $(\mathbf{b})$ is the magnification of the EIS spectrum of $\mathrm{CoP} / \mathrm{FeP}_{4} @ \mathrm{CNT}$. (c) $\mathrm{N}_{2}$ adsorption/desorption isotherms, and (d) pore-size distribution plots of CoFeP and $\mathrm{CoP} / \mathrm{FeP}_{4} @ \mathrm{CNT}$. 
In addition to the electrochemical characterization methods described above, the long-term stability of materials is often used as a benchmark to judge the performance of the OER. As shown in Figure 7a, there is no obvious change at $10 \mathrm{~mA} \mathrm{~cm} \mathrm{c}^{-2}$ after $18 \mathrm{~h}$ tests. Furthermore, it was found that $\mathrm{CoP} / \mathrm{FeP}_{4} @ \mathrm{CNT}$ could still coincide well with the initial one after 1000 cycles, which indicated that $\mathrm{CoP} / \mathrm{FeP}_{4} @ \mathrm{CNT}$ has excellent long-term stability and has a great prospect for future applications of the OER.
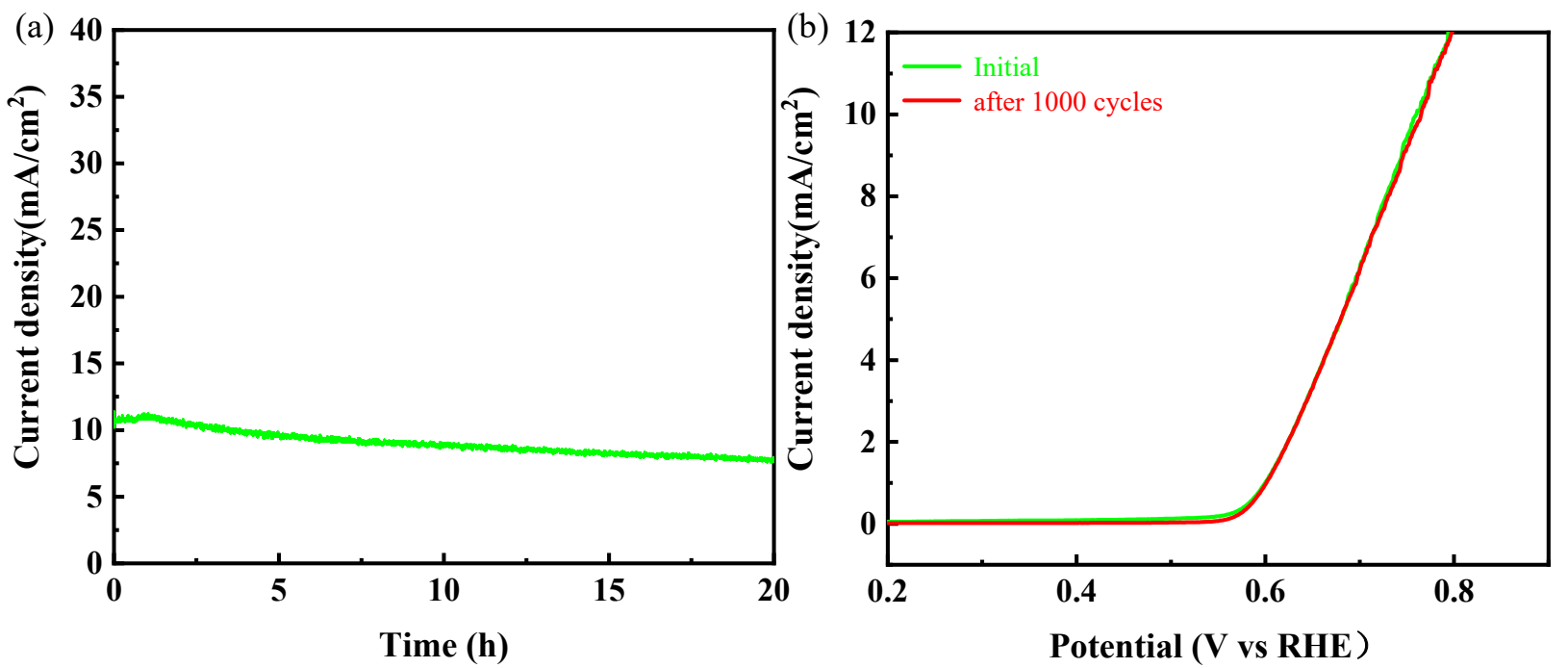

Figure 7. (a) $i \sim t$ curve of $\mathrm{CoP} / \mathrm{FeP}_{4} @ \mathrm{CNT}$ with the current density of $10 \mathrm{~mA} \mathrm{~cm}^{-2}$ in $1 \mathrm{M} \mathrm{KOH}$ solution at $1.533 \mathrm{~V}$. (b) LSV curves of $\mathrm{CoP} / \mathrm{FeP}_{4} @ \mathrm{CNT}$ before and after 1000 cycles.

\section{Conclusions}

In summary, hollow $\mathrm{CoP} / \mathrm{FeP}_{4}$ heterostructural nanorods interwoven by carbon nanotubes were synthesized by a facile hydrothermal reaction and a subsequent phosphorization process. The $\mathrm{CoP} / \mathrm{FeP}_{4} @ \mathrm{CNT}$ hybrid shows excellent OER performance with a low overpotential of $301 \mathrm{mV}$ to deliver $10 \mathrm{~mA} \mathrm{~cm}^{-2}$ and an extremely low Tafel slope of $48 \mathrm{mV}$ $\mathrm{dec}^{-1}$. The remarkable catalytic properties are attributed to its unique nanoarchitecture: the hollow structure of $\mathrm{CoP} / \mathrm{FeP}_{4}$ nanorods interwoven by CNT. Furthermore, the interface between $\mathrm{CoP}$ and $\mathrm{FeP}_{4}$ guarantee abundant active sites and a large electrochemical active specific surface area to improve the OER activity; the $\mathrm{CoP} / \mathrm{FeP}_{4}$ heterostructure induced electronic modulation, and the highly conductive $\mathrm{CNT}$ skeleton facilitate the electron transfer thus enhances OER performance. This work provides a strategy to rationally design and facilely fabricate a bimetallic phosphide heterojunction with unique nanoporous architecture with an enhanced OER performance.

Supplementary Materials: The following are available online at https:/ / www.mdpi.com/article/10 .3390/nano11061450/s1, Figure S1. XRD pattern of the CoFe-LDH@CNT precursor, Figure S2. The XPS survey spectrum of $\mathrm{CoP} / \mathrm{FeP}_{4} @ \mathrm{CNT}$, Figure S3. SEM morphology images of (a) CoFe-LDH, (b) CoFeP, Figure S4. SEM images of CoFe-LDH @CNT from different magnifications, Figure S5. EDX spectrum of $\mathrm{CoP} / \mathrm{FeP}_{4} @ \mathrm{CNT}$, Figure S6. Voltammograms for the OER in an alkaline electrolyte.

Author Contributions: Software, Q.W.; formal analysis, Y.L. (Yanfang Liu); investigation, Y.L. (Yong Li); resources, Y.C. and S.W.; data curation, Z.S.; writing-original draft preparation, Y.L.; writingreview and editing, Y.C., B.W. and S.W.; supervision, Y.C. and S.W.; funding acquisition, Y.C. and S.W. All authors have read and agreed to the published version of the manuscript.

Funding: The research was financially supported by the National Natural Science Foundation of China (Grant Nos. 21773024 and 52062045), the Sichuan Science and Technology Program (Grant Nos. 2020YJ0324 and 2020YJ0262), and the Reformation and Development Funds for the Local Region Universities from the Chinese Government in 2020 (Grant No. ZCKJ 2020-11), and Central Government Funds for Local Scientific and Technological Development (Grant No. XZ202101YD0019C). 
Data Availability Statement: Data is available on the request from the corresponding author.

Conflicts of Interest: The authors declare no conflict of interest.

\section{References}

1. Ma, P.; Yang, H.; Luo, Y.; Liu, Y.; Zhu, Y.; Luo, S.; Hu, Y.; Zhao, Z.; Ma, J. Strongly Coupled Interface Structure in $\mathrm{CoFe} \mathrm{Co}_{3} \mathrm{O}_{4}$ Nanohybrids as Efficient Oxygen Evolution Reaction Catalysts. ChemSusChem 2019, 12, 4442-4451. [CrossRef]

2. Zhang, G.; Li, Y.; Xiao, X.; Shan, Y.; Bai, Y.; Xue, H.G.; Pang, H.; Tian, Z.; Xu, Q. In Situ Anchoring Polymetallic Phosphide Nanoparticles within Porous Prussian Blue Analogue Nanocages for Boosting Oxygen Evolution Catalysis. Nano Lett. 2021, 21, 3016-3025. [CrossRef]

3. Huang, Y.; Zhang, S.L.; Lu, X.F.; Wu, Z.P.; Luan, D.; Lou, X.W.D. Trimetallic Spinel $\mathrm{NiCo}_{2-\mathrm{x}} \mathrm{Fe}_{\mathrm{x}} \mathrm{O}_{4}$ Nanoboxes for Highly Efficient Electrocatalytic Oxygen Evolution. Angew. Chem. Int. Ed. Engl. 2021. [CrossRef]

4. Wu, Y.; Xiao, Z.; Jin, Z.; Li, X.; Chen, Y. The cobalt carbide/bimetallic CoFe phosphide dispersed on carbon nanospheres as advanced bifunctional electrocatalysts for the ORR, OER, and rechargeable Zn-air batteries. J. Colloid Interface Sci. 2021, 590, 321-329. [CrossRef]

5. Wen, L.; Zhang, X.; Liu, J.; Li, X.; Xing, C.; Lyu, X.; Cai, W.; Wang, W.; Li, Y. Cr-Dopant Induced Breaking of Scaling Relations in CoFe Layered Double Hydroxides for Improvement of Oxygen Evolution Rection. Small 2019, 15, e1902373. [CrossRef] [PubMed]

6. Hirai, S.; Morita, K.; Yasuoka, K.; Shibuya, T.; Tojo, Y.; Kamihara, Y.; Miura, A.; Suzuki, H.; Ohno, T.; Matsuda, T.; et al. Oxygen vacancy-originated highly active electrocatalysts for the oxygen evolution reaction. J. Mater. Chem. A 2018, 6, 15102-15109. [CrossRef]

7. Lu, Y.; Hou, W.; Yang, D.; Chen, Y. CoP nanosheets in-situ grown on N-doped graphene as an efficient and stable bifunctional electrocatalyst for hydrogen and oxygen evolution reactions. Electrochim. Acta 2019, 307, 543-552. [CrossRef]

8. Jin, W.; Liu, F.; Guo, X.; Zhang, J.; Zheng, L.; Hu, Y.; Mao, J.; Liu, H.; Xue, Y.; Tang, C. Self-supported CoFe LDH/Co 0.85 Se nanosheet arrays as efficient electrocatalysts for the oxygen evolution reaction. Catal. Sci. Technol. 2019, 9, 5736-5744. [CrossRef]

9. Feng, H.; Sun, X.; Guan, X.; Zheng, D.; Tian, W.; Li, C.; Li, C.; Yan, M.; Yao, Y. Construction of interfacial engineering on CoP nanowire arrays with CoFe-LDH nanosheets for enhanced oxygen evolution reaction. FlatChem 2021, 26, 100225. [CrossRef]

10. Liu, S.; Zhu, J.; Sun, M.; Ma, Z.; Hu, K.; Nakajima, T.; Liu, X.; Schmuki, P.; Wang, L. Promoting the hydrogen evolution reaction through oxygen vacancies and phase transformation engineering on layered double hydroxide nanosheets. J. Mater. Chem. A 2020, 8, 2490-2497. [CrossRef]

11. Yue, X.; Ke, W.; Xie, M.; Shen, X.; Yan, Z.; Ji, Z.; Zhu, G.; Xu, K.; Zhou, H. Amorphous CoFe(OH) hollow hierarchical structure: An efficient and durable electrocatalyst for oxygen evolution reaction. Catal. Sci. Technol. 2020, 10, 215-221. [CrossRef]

12. Bae, D.; Seger, B.; Vesborg, P.C.; Hansen, O.; Chorkendorff, I. Strategies for stable water splitting via protected photoelectrodes. Chem. Soc. Rev. 2017, 46, 1933-1954. [CrossRef]

13. Yu, J.H.; Cheng, G.Z.; Luo, W. Hierarchical NiFeP microflowers directly grown on Ni foam for efficient electrocatalytic oxygen evolution. J. Mater. Chem. A 2017, 5, 11229-11235. [CrossRef]

14. Wang, X.Q.; Chen, Y.F.; Qi, F.; Zheng, B.J.; He, J.R.; Li, Q.; Li, P.J.; Zhang, W.L.; Li, Y.R. Interwoven WSe2 /CNTs hybrid network: A highly efficient and stable electrocatalyst for hydrogen evolution. Electrochem. Commun. 2016, 72, 74-78. [CrossRef]

15. Wang, B.; Hu, Y.; Yu, B.; Zhang, X.J.; Yang, D.X.; Chen, Y.F. Heterogeneous CoFe-Co8FeS8 nanoparticles embedded in CNT networks as highly efficient and stable electrocatalysts for oxygen evolution reaction. J. Power Sources 2019, 433, 126688. [CrossRef]

16. Chen, S.Y.; Bi, F.F.; Xiang, K.; Zhang, Y.; Hao, P.P.; Li, M.H.; Zhao, B.; Guo, X.F. Reactive Template-Derived CoFe/N-Doped Carbon Nanosheets as Highly Efficient Electrocatalysts toward Oxygen Reduction, Oxygen Evolution, and Hydrogen Evolution. ACS Sustain. Chem. Eng. 2019, 7, 15278-15288. [CrossRef]

17. Hu, Y.; Guan, D.G.; Yu, B.; Hou, W.Q.; Zheng, B.j.; Zhang, W.L.; Chen, Y.F. Scalable synthesis of $\mathrm{Mo}_{2} \mathrm{C} / \mathrm{CNT}$ networks as highly efficient and stable electrocatalyst for hydrogen evolution reaction. Electrochim. Acta 2018, 263, 192-200. [CrossRef]

18. Tian, C.; Yang, T.; Liu, Z.; Qing, Y.; Zhang, B.; Zhou, J.; Wu, Y. Well-aligned arrangement CoFe nanoparticles assisted with cellulose nanofibrils for efficient oxygen evolution reaction. Appl. Surface Sci. 2020, 510, 145484. [CrossRef]

19. Liang, C.; Zou, P.; Nairan, A.; Zhang, Y.; Liu, J.; Liu, K.; Hu, S.; Kang, F.; Fan, H.J.; Yang, C. Exceptional performance of hierarchical $\mathrm{Ni}-\mathrm{Fe}$ oxyhydroxide@NiFe alloy nanowire array electrocatalysts for large current density water splitting. Energy Environ. Sci. 2020, 13, 86-95. [CrossRef]

20. Samanta, A.; Raj, C.R. Catalyst Support in Oxygen Electrocatalysis: A Case Study with CoFe Alloy Electrocatalyst. J. Phys. Chem. C 2018, 122, 15843-15852. [CrossRef]

21. Kang, S.; Ham, K.; Lee, J. Moderate oxophilic CoFe in carbon nanofiber for the oxygen evolution reaction in anion exchange membrane water electrolysis. Electrochim. Acta 2020, 353, 136521. [CrossRef]

22. Feng, L.; Li, A.; Li, Y.; Liu, J.; Wang, L.; Huang, L.; Wang, Y.; Ge, X. A Highly Active CoFe Layered Double Hydroxide for Water Splitting. Chempluschem 2017, 82, 483-488. [CrossRef]

23. Zhou, L.-L.; Pan, D.-S.; Guo, Z.-H.; Song, J.-L. Two-dimensional bimetallic CoFe selenite via metal-ion assisted self-assembly for enhanced oxygen evolution reaction. New J. Chem. 2020, 44, 20148-20154. [CrossRef]

24. Liu, Y.; Hu, Y.; Ma, P.; Li, F.; Yuan, F.; Wang, S.; Luo, Y.; Ma, J. Amorphous CoFe Double Hydroxides Decorated with N-Doped CNTs for Efficient Electrochemical Oxygen Evolution. ChemSusChem 2019, 12, 2679-2688. [CrossRef] 
25. Hung, T.F.; Cheng, W.J.; Chang, W.S.; Yang, C.C.; Shen, C.C.; Kuo, Y.L. Ascorbic Acid-Assisted Synthesis of Mesoporous Sodium Vanadium Phosphate Nanoparticles with Highly sp2-Coordinated Carbon Coatings as Efficient Cathode Materials for Rechargeable Sodium-Ion Batteries. Chem. A Eur. J. 2016, 22, 10620-10626. [CrossRef] [PubMed]

26. Wang, Z.; Wei, C.; Zhu, X.; Wang, X.; He, J.; Zhao, Y. A hierarchical carbon nanotube forest supported metalphosphide electrode for efficient overall water splitting. J. Mater. Chem. A 2021, 9, 1150-1158. [CrossRef]

27. Yao, R.; Wu, Y.; Wang, M.; Li, N.; Zhao, F.; Zhao, Q.; Li, J.; Liu, G. Amorphous CoFeP/NC hybrids as highly efficient electrocatalysts for water oxidation. Int. J. Hydrog. Energy 2019, 44, 30196-30207. [CrossRef]

28. Yang, D.; Hou, W.; Lu, Y.; Zhang, W.; Chen, Y. Cobalt phosphide nanoparticles supported within network of N-doped carbon nanotubes as a multifunctional and scalable electrocatalyst for water splitting. J. Energy Chem. 2021, 52, 130-138. [CrossRef]

29. Bae, D.; Seger, B.; Hansen, O.; Vesborg, P.C.; Chorkendorff, I. Durability Testing of Photoelectrochemical Hydrogen Production under Day/Night Light Cycled Conditions. ChemElectroChem 2019, 6, 106-109. [CrossRef]

30. Singh, A.K.; Yasri, N.; Karan, K.; Roberts, E.P. Roberts Electrocatalytic Activity of Functionalized Carbon Paper Electrodes and Their Correlation to the Fermi Level Derived from Raman Spectra. ACS Appl. Energy Mater. 2019, 2, 2324-2336. [CrossRef]

31. Du, Y.; Qu, H.; Liu, Y.; Han, Y.; Wang, L.; Dong, B. Bimetallic CoFeP hollow microspheres as highly efficient bifunctional electrocatalysts for overall water splitting in alkaline media. Appl. Surf. Sci. 2019, 465, 816-823. [CrossRef]

32. Zhang, W.; Li, Y.; Zhou, L.; Zheng, Q.; Xie, F.; Lam, K.H.; Lin, D. Ultrathin amorphous CoFeP nanosheets derived from CoFe LDHs by partial phosphating as excellent bifunctional catalysts for overall water splitting. Electrochim. Acta 2019, $323,323$. [CrossRef]

33. Wang, B.; Chen, Y.; Wang, X.; Ramkumar, J.; Zhang, X.; Yu, B.; Yang, D.; Karpuraranjith, M.; Zhang, W. rGO wrapped trimetallic sulfide nanowires as an efficient bifunctional catalyst for electrocatalytic oxygen evolution and photocatalytic organic degradation. J. Mater. Chem. A 2020, 8, 13558-13571. [CrossRef]

34. Li, W.; Chen, Y.; Yu, B.; Hu, Y.; Wang, X.; Yang, D. 3D hollow Co-Fe-P nanoframes immobilized on N,P-doped CNT as an efficient electrocatalyst for overall water splitting. Nanoscale 2019, 11, 17031-17040. [CrossRef] [PubMed]

35. Jiang, D.; Xu, S.; Quan, B.; Liu, C.; Lu, Y.; Zhu, J.; Tian, D.; Li, D. Synergistically coupling of Fe-doped CoP nanocubes with CoP nanosheet arrays towards enhanced and robust oxygen evolution electrocatalysis. J. Colloid Interface Sci. 2021, 591, 67-75. [CrossRef]

36. Wang, B.; Chen, Y.F.; Wu, Q.; Lu, Y.J.; Zhang, X.J.; Wang, X.Q.; Yu, B.; Yang, D.X.; Zhang, W. L A co-coordination strategy to realize janus-type bimetallic phosphide as highly efficient and durable bifunctional catalyst for water splitting. J. Mater. Sci. Technol. 2021, 74, 11-20. [CrossRef] 